\title{
Application of Task-Driven Teaching Model in Skill-Oriented Distance Education --Taking Windows Network Operating System as an Example
}

\author{
Canjun Li, Xinguo Liu, Liqin Xia and Song Fang \\ Department of Computer Science, Hunan Radio \&TV University, Changsha, China \\ E-mail: li_canjun@163.com,14528139@qq.com,330383611@qq.com,2348763@qq.com
}

\begin{abstract}
Thorough analyzing the problems of traditional skill-oriented distance education and taking Windows Network Operating System as an example, this paper applies the task-driven teaching method to reconstruct the content of the skill-oriented curriculum, which has achieved decent teaching efficiency. What's more, the problems in the application have been also pointed out.
\end{abstract}

Keywords- task-driven teaching model, network operating system, teaching

\section{TEACHING CHARACTERISTICS AND PROBLEMS IN THE TRADITIONAL SKILL-ORIENTED DisTANCE EDUCATION}

There is a fundamental difference between the distance education, the application-oriented profession focused on cultivating practical talent, and the traditional education, focused on the academic teaching. As for the former one, it puts emphasis on the professional application ability rather than the cultivation of non-professional theoretical basis. The skill-oriented curriculum is a key process to link the theoretical courses with the practical ones so as to cultivate student's abilities on solving practical problems, which decides the particularity of the applied teaching model-the skill-oriented curriculum in the context of distance education should adopt distinctive teaching model which is different from the traditional one. Windows Network Operating System is a skill-oriented curriculum. It is also a professional one for the computer science and technology as well as the computer network technology. Both of them have strong theoretical and piratical properties. As for the main teaching contents of the Windows Network Operating System, it covers network system management, the allocation, maintenance and management of network server in the network operating system of Windows Server 2008, as well as builds and manages local area network utilizing simple interconnecting device. What's more, it focuses on the practical technology and application of the web service to cultivate student's professional skills of network design, establishment, safeguard and management. After passing this curriculum, students can allocate relevant web service, establish company local area network and maintain and manage this network in accordance with the company's practical requirements.
Our school has established this curriculum since 2004, and the research group members are all studying and exploring this teaching model. At first, we adopted the traditional teaching method-theory prior to practice- to separate theory from practice. In other words, the theoretical lesson was carried out in the multi-media classroom and the experimental lesson in the computer room. Based on students' assessment and teacher's feedback, there are some problems in this teaching model:

A. The traditional teaching model puts emphasis on theory rather than practice.

As the teaching of theory and practice has been departed, students cannot understand the knowledge thoroughly without checking by practice.

\section{B. The traditional practice goes against the cultivation of innovation.}

In traditional theoretical teaching model, the practical teaching (curriculum experiment) only refers to the theory simulation and simple application, which is bad for the cultivation of innovation and goes against the modern educational idea of focusing on the cultivation of student's technological innovative ability.

C. The content of traditional skill-oriented curriculum is too numerous and jumbled, which is bad for the cultivation of application ability.

While the involved content in skill-oriented curriculum is a collection of series of technology application to solve the practical problems in engineering project, the limited time of traditional teaching always cannot take into account of all technological knowledge with a result that the students can only grasp some scattered knowledge points. They cannot understand the overall structure and the inner consistency, so leave alone the cultivation of application abilities.

\section{The students have weak initiative to study.}

The traditional learning style is a kind of passive one, which is less efficient. In the traditional teaching model of "the teacher teaching and the students learning", students always study passively. What's more, the knowledge points are superficial to attract student's attention, so that 
even if the students can insist studying, they will lose the initiative for lacing achievement in the learning process.

These existing problems make the reform for the skilloriented curriculum timely. Since from 2010, our school has probed to the task-driven teaching model of Windows Network Operating System to try to solve the problems just mentioned above.

\section{DESIGN THOUGHT OF SKILL-ORIENTED CURRICULUM TEACHING MODEL}

Corresponding with the characteristics of distance education and adult learning, the skill-oriented curriculum teaching model is designed in accordance with the current employment of students and following the teaching concept of "one approach, two fusions and three dockings". It has formed the target of the installation, application and inspection of the network operating system sever and broken the design thought of subject system. Surrounding the basic target needs, four learning-situated contextsWindows system management, Windows sever establishment, Windows safety maintenance and general establishment of severs to organize the content, highlight network's installation, settings and application. So that the learners can master the essentials on the basis of overall scheme design and enhance the dependency between the curriculum content and the requirements of occupation post.

One approach: Through the cooperation with The Great Wall Information Group and CITIC Communication Hunan Branch as well as the investigation of network manager, we can get the typical work task and real case.

Two fusions: By means of the fusion between full-time teachers and professions as well as vocational ability and vocational quality, we can guarantee the content of Widows Sever conforms to learner's requirements of employment.

Three dockings: Through the criteria of course outline, teaching content and qualification authentication, as well as the docking between learning process and working process, we can display the "The teaching does unites" project and the task materials.

\section{IMPORT OF TASK-DRIVEN TEACHING}

The "task-driven" teaching thought, based on constructivism, is basically in correspond with the "learning for practice" advocated by Confucius 2,000 years ago. According to the constructivism learning theory, the learning process is not just learning passively, but constructs the knowledge actively. It converts the traditional teaching concept that focusing on teaching knowledge to interactive means featuring problem-solving and multi-tasks performing. What's more, it converts the representation teaching to exploration teaching, so that every student can solve the problems to keep a positive learning state in accordance with the interpretation of current problems and his own experience. In a word, the study is not a knowledge shift or transfer, but a process that the students establish their own knowledge and experience. By means of interaction between new experience and the old one, students can fulfill their knowledge deposits and improve their abilities.

\section{THE TASK-DRIVEN RECONSTRUCTION OF SKILL- ORIENTED CURRICULUM CONTENT}

The task-driven reconstruction of skill-oriented curriculum content follows the thought in which is based on the basic teaching target of the course, and thoroughly break the curriculum design of subject system, combining the employability of students. Thus, the correlation requirement of course contents and occupation competence enhance.

In the process of teaching design on the course of Windows Network Operating System macro, the research group refers to the actual situation of the enterprises, giving students a kind of environment with experiment training, in which the work item is designed into a number of tasks. It is a number of teaching task items that support the construction and application of an enterprise network.

The knowledge reconstruction of the specific course content can be divided into the following two steps:

\section{A. The Selection of Teaching Total Item}

Referring to the actual situation of the enterprise, "the network construction and management based on Windows Server 2008" is selected as the teaching total item. The topological structure of the item is as shown in figure1.

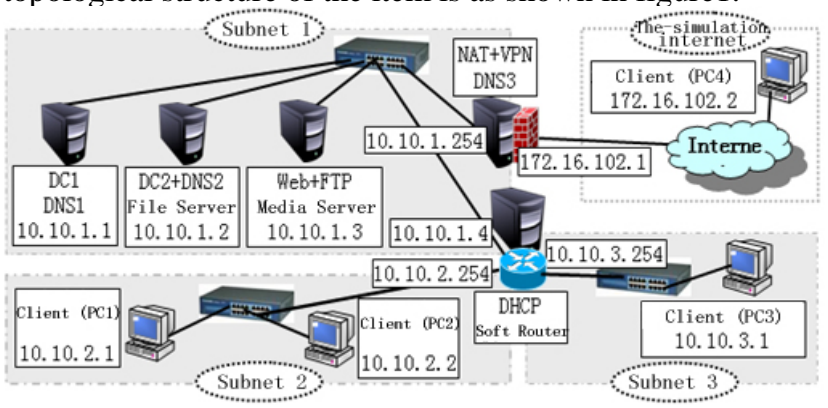

Figure 1. The total project topology

\section{B. The Selection of Sub-items (Task).}

Referring to the actual situation of the enterprise, based on the requirement of the theory and practice of knowledge with analyzing the teaching total item, the course have divided "the network construction and management based on Windows Server 2008", the great item of the enterprise, into the following fifteen sub-items.

Item 1 Windows Server Installation and Basic Configuration;

Item 2 Work Group and Local Account Management;

Item 3 Establishment and Management of the Field;

Item 4 Disk and Data Storage Management;

Item 5 The Construction of DHCP Server;

Item 6 The Construction of DNS Server;

Item 7 The Construction of WWW Server;

Item 8 The Construction of FTP Server;

Item 9 The Construction of Exchange Server; 
Item 10 The Construction of Media Server;

Item 11 The Construction of Router, NAT, VPN Server;

Item 12 Permissions, Backup and Implementation of Storage Security by Recovery;

Item 13 Usage Security Strategy and Implementation of Firewall Access Security;

Item 14 Using PKI and Implementation of Transfer Security by Certificate;

Item 15 Integrated Cases

All these tasks are combined with the actual situation and is all kinds of service in use on the Internet, such as DHCP, DNS, WEB etc. When students are surfing on the daily Internet, consciously or unconsciously, they have used these tasks. However, they just do not especially care about the background service operation. And if students have the course of Network Principle, through their searching information and the teacher's explanation, it will be little difficult for them to complete these tasks.

\section{SPECIFIC IMPLEMENTATION}

According to the characteristics of distance education students, the task-driven teaching in the skill-oriented curriculum is carried out by the study group (individual) as the unit. Understand the work task; for each task, have a discussion in the group under the guidance of teachers; according to the work process and link, divide it into specific work tasks; analysis the method to solve the problem; through the group competitive bidding, present the ideas to solve the problem of the group (individual); analyze the new potential problems and solutions in the process of actual practice and operation. We take the following Item 5 The Construction of DHCP Server of Windows Network Operating System project as an example, and introduce the implementation process of task-driven method teaching.

A. The Reception of Task (the analysis of business needs).

Distance education students are from the frontline of work, the analysis of business needs relatively has certain advantage. When teachers and students work together for the analysis of business needs, it will be much smoother to make clear the task, according to the specific task to organize the teaching.

Background Requirements of the Enterprises in Item 5 are as Follows:

Enterprise construction has set up the enterprise network. However, with the popularity of the notebook computer, the phenomenon of workers' mobile office becomes more and more. When the computer moves from one network to another network, it needs to access IP address, gateway and other information of the new network again, and install the computer as well. In this way, the client needs to know the disposition condition of the whole network, also need to know which network segment do they lay in, which IP address is free and the default gateway and other much information, which not only make the user feel tedious, but also bring many difficulties for the network administrator to project the network and allocate the IP address. Network users need no matter what position do they lay in the network, and they do not need to prepare IP address, default gateway and other information to surf the internet.

The above requirements of the item can be simplified as: on the condition of already set-up enterprise network, how to simplify the network settings, and to improve the convenience of mobile office?

Prior to the completion of the item, first of all, we should to the planning of the entire network, and determine the division of network segment and the number of the host each network segment may exist and other information.

Students in small groups (individual) as a unit will understand the "The Construction of DHCP Server" task. The teacher will introduce the concept of DHCP, which will let the students have a preliminary understanding of DHCP. On this basis, the teacher will guide the group to discuss, according to the work process and link to explode and set up the installation and authorization, action scope installation and other work tasks of DHCP Server. Then, through the group cooperation and competitive bidding, present the ideas to solve the problem of the group, and analyze the new potential problems and solutions. Finally the task should contain at least the following three basic sub-tasks, namely the installation and authorization of DHCP, the creation and activation of action scope, the retention of IP.

\section{B. The plan of task (the formulation of item plan).}

Determine the work procedures of tasks; identify each action procedure of work tasks; divide the total task of the item according to the work process and link. Adopt the organization form of grouping instruction, which enables the student through independent learning, collaborative learning to finish the task. Around the specific tasks, students who are based on the information of knowledge and skills decide which ones used to complete the task, and select and plan the task's methods and steps, and make related item plan.

\section{The implement of task (operation steps).}

According to the task planning results of No.B, the group (individual) works together, in order to complete various task planning, complete the related task.

\section{The completion of task (test and record).}

Conduct the records and tests of the completion condition of the task, and inspect completion condition of the plan, and make a last summary on the previous learning process.

\section{E. Evaluation.}

Conduct the examination and evaluation of the completion condition of the previous task results. Each learning group (individual) merges the results of each subtask, and forms the total task results, and sets the display platform, on which let the group representatives to show 
their task works and item results, in order to assess the item results between teachers and students.

\section{THE EFFECT OF TASK-DRIVEN TEACHING METHOD IN SKILL-ORIENTED CURRICULUM}

According to the characteristics of the skill-oriented curriculum, adopt the task-driven teaching and learning methods, and expand to learn around the task, which can provide the students with the situation of experiencing the practice and understanding the problems; test and summarize the learning process on the basis of the completion condition of the task, which has changed the learning state of students and made the students actively construct an intelligent learning system of the exploration, practice, thinking, application, solving. Thus, its teaching effect should be more effective than that of the traditional teaching method.

Since 2010, the research group has conducted the teaching study of task-driven teaching method on the basis of the Windows Network Operating System in the Network classes among 2009-2013 grades. In the examination of the comprehensive practical training at the end of semester, the average number of the completion of the task conducted by the students with the adoption of task-driven teaching method is 10 , and the average number before 2010 of the completion of the task conducted by normal students is 6. By contrast, the students taught within task-driven teaching method teaching class get enhanced in their hands-on abilities, in the mastery degree of the theory, in the ability to analyze problems and to solve the problem, and in the students' abilities of the autonomous learning and uniting and cooperating with others. These are the evidence for skill-oriented curriculums using task-driven teaching method to support its effectiveness in practice.

\section{THE Notice NEEDS FocUS ON TASK-DRIVEN TEACHING WITH IMPLEMENTATION OF SKILL-ORIENTED CURRICULUMS.}

"Task" is always proposed around one or more identified learning objectives. Teachers in the implementation of the task-driven teaching need to pay attention to some problems of skill curriculums.

\section{A. The higher requirements to teachers.}

The level of the teachers plays a very important role in the process of teaching. Teachers on the basis of the framework of curriculum overall learning objectives divide the overall goals into smaller ones, and refine the content of each learning module one by one into each "sub-task" that is easy to grasp, through these small "subtask", the overall learning objectives being reflected. The process should according to the characteristics of taskdriven teaching method reconstruct the content of curriculum knowledge.

\section{B. Design is vital to the task.}

To ensure the task-driven teaching method, teachers in the design of "task", should combine with the actual situation to design a reasonable teaching task. Each task should meet with the following conditions.

1) Make the students be interested in.

2) Should combine with the actual condition.

3) The difficulty level should be moderate that lets the student complete through some efforts.

\section{Avoid task-driven formalization and simplification.}

Task-driven teaching method is indeed a unique advantage to achieve the teaching goal, and not to simplify the task as the simple decomposition of teaching objectives. Avoid "formalism", and only the task-driven teaching that show intrinsic link between knowledge and show the essence of things has the practical significance which can achieve good results.

\section{Focus on the cultivation of the humanities spirit in task-driven teaching.}

The curricular teaching based on task-driven method, not only needs for the scientific culture of students' abilities on the technical operation and the abilities to solve practical problems, at the same time should cultivate students in the goal of teaching and also in rich emotion target, such as the deep humanistic knowledge. Taskdriven teaching form make the teaching environment situational and problematic, while teaching process requires both to be originated from concrete situation and to surpass the specific situation, to achieve the highest realm combining with the knowledge, skills, emotions. Valuable task-driven design needs to focus on the human spirit. In addition to enable students to reach certain cognitive goals and skills goals, it also needs to have a positive influence on students' way of thinking, moral emotion, behavioral habits, personality shaping and even value orientation.

\section{CONCLUSION}

The task-driven teaching method is only one of various teaching methods. We take the Windows Network Operating System course as an example, in which we conduct the teaching exploration of the task-driven method in the skill-oriented curriculum. Some practical effects have been made in practice. But in the process of our teaching when we face the practical teaching objects and teaching contents, it should be combined with the actual situation to have certain flexible application of teaching method, such as the students level, course characteristics, teachers quality and practice teaching, even if the choice of this teaching method in teaching, also do not apply mechanically. Even if this kind of teaching method is selected, instead of accepting and imitating blindly, we should do some corresponding adjusts according to the actual situation, in order to improve the teaching quality and achieve the optimal teaching effect.

\section{REFERENCES}

[1] Tan Fangyong ect.. Application of the Project Teaching Method in the Course Chain of the Network Operating System Management [Z]. Journal of Wuhan Institute of Technology, 2009, 8 (2) 
[2] Wang Heping ect.. The Curriculum Design and Practice Based on the Working Process of the Linux Network Operating System [Z]. Vocational \& Technical Education Forum.2010 (14)

[3] Wu Jing. The Comparison of Similarities and Differences between the Project Teaching Method and Task-driven Teaching Method [Z]. 2011, 10 (7) Journal of Beijing Vocational and Technical Institute of Industry, 2011,10 (3)

[4] Liu Qing ect.. The Teaching Research of Higher Vocational Colleges Based on Linux Network Operating System [Z]. 2010, 10 (4) Journal of Chuzhou Vocational and Technical College
[5] Zhang Zhijun. The Joint Utilization of the Task-driven Teaching Method and the Project Teaching Method in Higher Vocational Teaching [Z]. Journal of Wuhan Institute of Shipbuilding Technology 2010, 9 (3)

[6] Ju Lifeng ect.. The new ideas of Teaching Reform in Network Operating System [Z]. Modern Enterprise Education. 2009 (14)

[7] Chen Xiaojun ect.. The Brief Study on the Task-driven Teaching [Z]. China Science and Technology Information .2006 (16) 